\title{
Influência geológica e antrópica na qualidade da água de um córrego no Pantanal Norte, Brasil
}

Estudos sobre a qualidade dos recursos hídricos são uma importante ferramenta para a gestão dos ambientes aquáticos. Assim, buscou-se analisar a qualidade da água do córrego Jacobina na região rural de Cáceres/MT, Pantanal Norte, em relação à litologia e ao uso e cobertura da terra do entorno da bacia. Para tanto, a bacia foi compartimentada em alto, médio e baixo cursos e a amostragem compreendeu o período de seca e cheia, característicos do Pantanal. Para o levantamento das unidades geológicas da bacia foi elaborado um mapa temático utilizando imagens de satélite Landsat TM 5 e TM 8 . A identificação do uso e cobertura da terra do entorno foi levantada através de visitas in loci com aplicação de questionários nas propriedades rurais que abrangem o córrego. Em cada compartimento um ponto de coleta de água foi adotado. Foram analisadas 25 variáveis limnológicas e o Índice de Qualidade da Água (IQA) foi aplicado. Os resultados demonstraram que em geral, a qualidade da água do córrego Jacobina é 'Ótima' de acordo com os valores obtidos pelo cálculo do IQA e pela apresentação das variáveis que estiveram dentro do que preconiza a legislação vigente do CONAMA 357/05 e 430/11 e MS 2914/11. As características da água do córrego são possivelmente influenciadas pelo material rochoso, em sua maioria calcário, demonstradas pelos parâmetros de $\mathrm{Ca} 2+, \mathrm{Mg} 2+$, alcalinidade e $\mathrm{pH}$. Desta forma, este estudo permitiu relacionar as atividades desenvolvidas no entorno do córrego Jacobina, bem como as características naturais do ambiente como a com a qualidade da água.

Palavras-chave: Limnologia; IQA; Geologia; Uso da terra.

\section{Geological and anthropic influence on the water quality of a northern Pantanal Stream, Brazil}

\begin{abstract}
Studies about the quality of water resources are an important tool for the management of aquatic environments. Thus, we sought to analyze the water quality of the Jacobina stream in the rural region of Cáceres/MT, Northern Pantanal, in relation to lithology and the use and coverage of land around the basin. For this purpose, the basin was compartmentalized in high, medium and low courses and the sampling comprised the dry and flood period, which are characteristic of the Pantanal. For the survey of the geological units of the basin, a thematic map was elaborated using satellite images Landsat TM 5 and TM 8 . The identification of the use and coverage of the surrounding land was raised through on-site visits with the application of questionnaires on the rural properties that cover the stream. In each compartment, a water collection point was adopted. 25 limnological variables were analyzed and the Water Quality Index (WQI) was applied. The results showed that, in general, the water quality of the Jacobina stream is 'Excellent' according to the values obtained by calculating the WQI and by presenting the variables that were within the limits of the current legislation of CONAMA 357/05 and 430/11 and MS 2914/11. The stream waters are possibly influenced by the rocky material, mostly limestone, demonstrated by the parameters of $\mathrm{Ca} 2+, \mathrm{Mg} 2+$, alkalinity and $\mathrm{pH}$. Thus, this study made it possible to relate the activities developed around the Jacobina stream, as well as the natural characteristics of the environment, such as water quality.
\end{abstract}

Keywords: Limnology; WQI; Geology; Land Use.

Topic: Uso de Recursos Naturais

Reviewed anonymously in the process of blind peer.
Received: 09/08/2020

Approved: 25/09/2020
Beatriz Ferraz Bühler (iD)

Universidade do Estado de Mato Grosso, Brasil

http://lattes.cnpq.br/4989365701215549

http://orcid.org/0000-0003-3351-609X

bfbuhler@gmail.com

Ernandes Sobreira Oliveira Junior (iD)

Universidade do Estado de Mato Grosso, Brasil

http://lattes.cnpq.br/7461346615427709

http://orcid.org/0000-0002-6953-6917

ernandes.sobreira@gmail.com

Célia Alves de Souza (iD

Universidade do Estado de Mato Grosso

http://lattes.cnpq.br/4260661798494235

http://orcid.org/0000-0002-9068-9328

celiaalvesgeo@globo.com
Referencing this:

BÜHLER, B. F.; OLIVEIRA JUNIOR, E. S.; SOUZA, C. A.. Influência geológica e antrópica na qualidade da água de um córrego no Pantanal Norte, Brasil. Revista Ibero Americana de Ciências Ambientais, v.11, n.5, p.549-565, 2020. DOI: http://doi.org/10.6008/CBPC2179-6858.2020.005.0050 


\section{INTRODUÇÃO}

Os múltiplos usos e manejo dos recursos aquáticos têm produzido pressões ambientais de maneira a comprometer sua quantidade e qualidade através da entrada de diferentes substâncias nos corpos d'água, causando poluição e escassez. Neste sentido algumas legislações nacionais foram criadas no intuito de controlar a degradação dos recursos hídricos, entre elas, destaca-se a Portaria do Ministério da Saúde - MS 2914/2011 que estabelece que toda a água que seja destinada ao consumo humano deve obedecer a um padrão de potabilidade que diminua a ocorrência de doenças de veiculação hídrica e as Resoluções do Conselho Nacional de Meio Ambiente - CONAMA 357/2005 e 430/2011 cujos objetivos são, respectivamente, estabelecer padrões de qualidade da água e classificar os corpos hídricos de acordo com seus usos preponderantes (BRASIL, 2011).

A origem de diferentes substâncias que entram nos corpos d'água pode ser de fonte natural (e.g. tipo de solo e de rochas da bacia hidrográfica), mas também de fonte antrópica (e.g. irrigação da agricultura, navegação, recreação, pastagem). Neste sentido, muitos estudos têm destacado a relação entre a presença de agentes físicos, químicos e biológicos com os fatores naturais e/ou antrópicos presentes em uma bacia com a perspectiva de avaliar a qualidade da água nas escalas local e global (MONTEIRO et al., 2014; OLIVEIRA et al., 2017; SOUZA et al., 2014).

As legislações nacionais têm ainda sido bastante utilizadas em pesquisas científicas para avaliar a qualidade hídrica de um sistema (OLIVEIRA et al., 2017) seja para avaliar a influência de fatores ambientais e antrópicos nos mananciais (REIS et al., 2017) ou mesmo para que novas tendências de avaliação da qualidade da água sejam reportadas na literatura nacional, como a inclusão da modelagem matemática da qualidade hídrica de um rio conforme Oliveira Filho et al. (2017). Neste sentido, a qualidade de água do estado de Mato Grosso tem sido avaliada sob diversas vertentes, sempre utilizando métodos pautados nessas resoluções e portaria e tem demonstrado ser um importante instrumento de avaliação dos recursos hídricos em pequenas bacias como o rio Jauquara que abastece comunidades tradicionais na cidade de Barra do Bugres (FERREIRA et al., 2017) ou em bacias de grande porte como o rio Vermelho em Rondonópolis (SOUZA et al., 2014).

Em todo o mundo, o acesso e a qualidade da água tem sido amplamente investigada, seja pela ação de agricultura e agentes agroquímicos (LAMPTEY et al., 2013) ou através de discussões acerca da governança da água pela sua disponibilidade e/ou gestão (VALDÉS-PINEDA et al., 2014). Ademais, os aspectos geológicos, bem como a composição geoquímica dos corpos d'água tem sido amplamente utilizados na avaliação da qualidade do recurso hídrico conforme estudos desenvolvidos por Fok et al. (2013), Mosaad (2017), entre outros, indicando a influência direta do material rochoso na água da bacia em função dos elementos químicos encontrados.

Um dos instrumentos de avaliação da qualidade dos recursos hídricos que vem sendo utilizado em muitos estudos é o Índice de Qualidade da Água (IQA) que foi desenvolvido pela National Sanitation Foundation na década de 70 nos Estados Unidos e a partir do ano de 1975 a CETESB (Companhia Ambiental do Estado de São Paulo) passou a utiliza-lo em águas de abastecimento público com algumas adaptações 
(CETESB, 2014) e embora existam outros métodos de avaliar a qualidade hídrica, este é o principal índice de qualidade da água utilizado no país (ANA, 2015).

Embora muitos estudos destaquem a importância da qualidade da água no meio urbano, também os corpos hídricos rurais exercem grande importância na manutenção das comunidades, servindo para o abastecimento humano, dessedentação de animais, suprimento hídrico para plantações, recreação e higiene pessoal. Cidades do Pantanal são comumente cortadas por córregos, estes utilizados para seu abastecimento populacional urbano e rural.

O córrego Jacobina é um importante manancial que abrange a zona rural da cidade de Cáceres/MT no Pantanal e abastece muitas propriedades rurais da região para a irrigação agrícola, criação de gado e consequentemente pastagem além de abastecimento doméstico e recreação por parte da população (observação pessoal). Porém, este córrego corta a província serrana pantaneira e sofre influência geoquímica da formação rochosa. Desta forma, considerando que este é um canal fluvial de extrema importância para a comunidade local o presente estudo teve como objetivo avaliar a qualidade da água da bacia hidrográfica do córrego Jacobina correlacionando com o tipo de uso e ocupação do entorno da bacia e a geologia pela qual o córrego percorre no Pantanal Norte.

\section{MATERIAIS E MÉTODOS}

\section{Caracterização da área de estudo}

O Pantanal é um dos principais biomas da América do Sul com uma área total de aproximadamente $160.000 \mathrm{~km}^{2}$, abrangendo áreas inundáveis do Paraguai em $5.000 \mathrm{~km}^{2}$, Bolívia em $15.000 \mathrm{~km}^{2}$ e em sua maior porção no Brasil com 140.000 km² (JUNK et al., 2006) e neste, encontrando-se nos estados de Mato Grosso (Pantanal Norte) e Mato Grosso do Sul (Pantanal Sul) (BRASIL, 1982).

Esta planície de inundação apresenta características próprias de áreas que inundam sazonalmente de acordo com o fluxo hidrológico local. Portanto, duas estações bem definidas ocorrem no Pantanal: estação seca entre os meses de Maio a Setembro e estação chuvosa entre os meses de Outubro a Abril (JUNK et al., 2006) ocasionando pulsos de inundações que quando anuais ou mesmo excepcionais, são responsáveis pelas diferentes paisagens no Pantanal e consequentemente por alterações na biota local (SILVA et al., 2001).

O córrego Jacobina está localizado na região Sudoeste do Estado de Mato Grosso entre as coordenadas geográficas $16^{\circ} 11^{\prime} 51,6^{\prime \prime}$ a $16^{\circ} 17^{\prime} 04,4^{\prime \prime}$ de latitude Sul e $57^{\circ} 31^{\prime} 23.7^{\prime \prime}$ a $57^{\circ} 46^{\prime} 20,1^{\prime}$ de longitude Oeste. Suas nascentes localizam-se entre as Serras da Jacobina e da Campina, sendo que a nascente principal está localizada na Fazenda Córrego Fundo, à margem esquerda da rodovia BR-070 que liga os municípios de Cáceres à Várzea Grande.

A bacia possui área total de 446,33 km2 e o canal fluvial 52,68 km de extensão, percorrendo várias fazendas de atração turística, de criação de animais e diversos tipos de plantio como as fazendas Córrego Fundo, Jacobina, Figueira Branca, Goiana, Primavera, 4M, Campo Novo, Fordinho e Grendene, desaguando no rio Paraguai pela margem esquerda à altitude de $110 \mathrm{~m}$ aproximadamente, tornando-se um afluente do 
rio juntamente com os córregos da Laje, Grande e Fundo conforme Figura 1.

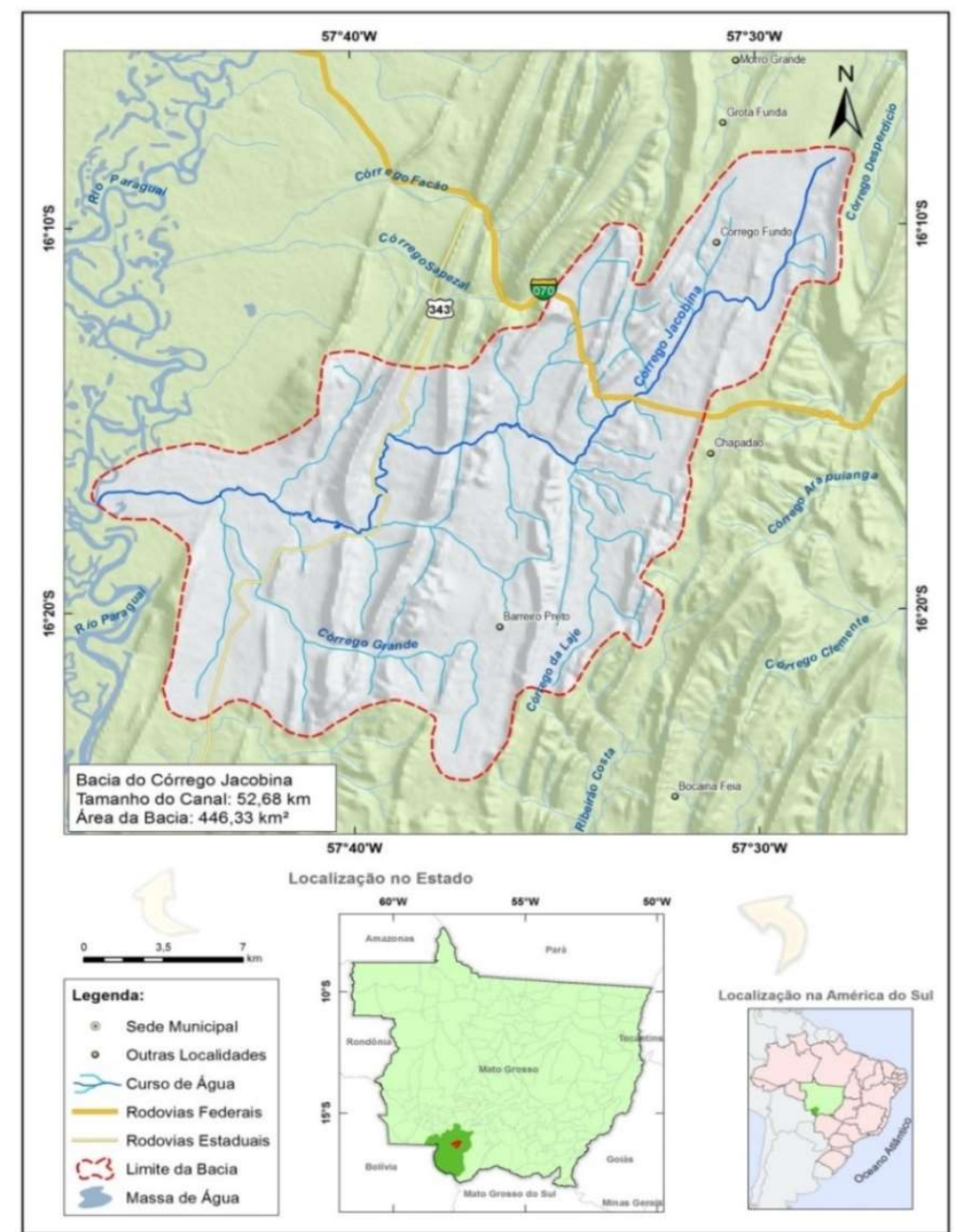

Figura 1: Mapa de localização do córrego Jacobina, em Cáceres/MT, Pantanal Norte, Brasil.

\section{Determinação dos pontos amostrais}

A área de estudo foi compartimentada em alto, médio e baixo curso. Em cada um dos compartimentos, um ponto amostral foi determinado para o levantamento das variáveis limnológicas assim organizados: Alto Curso - Ponto1; Médio Curso - Ponto 2; Baixo Curso - Ponto3. A determinação dos pontos amostrais levou em consideração a logística e acessibilidade por estradas rurais e/ou necessidade de navegação, no caso do baixo curso. Desta forma, pôde-se abranger maior número de propriedades para identificar os distintos usos da terra no entorno do córrego, bem como do recurso hídrico per se.

\section{Levantamento das características ambientais da bacia (geologia e uso e ocupação da terra)}

O levantamento da geologia da bacia foi realizado através de revisão bibliográfica considerando o Projeto RADAMBRASIL (1982) que permitiu, pela compilação de dados, a elaboração de mapa temático demonstrando as unidades geológicas que compreendem a bacia hidrográfica do córrego Jacobina através do software ArcGis, versão 10.1 utilizando imagens de satélite LANDSAT TM5 e TM8 em escala 1:210.000. Visitas in loci foram realizadas a fim de registrar (de forma escrita e fotográfica) a litologia do entorno da bacia. 
Para identificar o tipo de uso e ocupação da terra no entorno da bacia a área que compreende a bacia foi mapeada com auxílio de mapas de ocupação disponibilizado pelo Instituto Nacional de Colonização e Reforma Agrária (INCRA) do ano de 1985, bem como realizadas visitas in loci nas propriedades rurais com aplicação de questionário semiestruturado conforme Boni et al. (2005) em que os entrevistados foram perguntados sobre o tipo e frequência de uso da terra e da água. As entrevistas foram aplicadas no período de Fevereiro a Agosto/2015

\section{Levantamento das variáveis limnológicas e cálculo do IQA}

Foram levantadas 25 variáveis limnológicas nos períodos chuvoso (Fevereiro/2015) e estiagem (Julho/2015) dentre as quais, foram analisadas em laboratório de ensaios químicos e controle de qualidade da água ${ }^{2}$ : alcalinidade de bicarbonato, cálcio $\left(\mathrm{Ca}^{2+}\right)$, cloretos $\left(\mathrm{Cl}^{-}\right)$, demanda bioquímica de oxigênio (DBO $)$, demanda química de oxigênio (DQO), dureza total, fósforo total (PT), magnésio $\left(\mathrm{Mg}^{2+}\right)$, nitrato $\left(\mathrm{NO}_{3}{ }^{-}\right)$, nitrito $\left(\mathrm{NO}_{2}{ }^{-}\right)$, nitrogênio amoniacal, potássio $\left(\mathrm{K}^{+}\right)$, sódio $\left(\mathrm{Na}^{+}\right)$, sólidos suspensos, sólidos dissolvidos, sulfatos $\left(\mathrm{SO}_{4}{ }^{2-}\right.$ ) e resíduos totais. Os métodos de analises utilizados estão de acordo com Standard for the Examination of Water and Wastewater 22ㅇe edition, APHA, WEF, AWWA E ICR Microbial Laboratory Manual, U.S EPA (2012). As variáveis $\mathrm{pH}$, oxigênio dissolvido (OD), saturação de OD, temperatura e condutividade elétrica (CE) foram determinadas em campo através da sonda multiparamétrica (Hach, modelo HQ40d) e a variável turbidez foi levantada através do aparelho turbidímetro (Policontrol, modelo AP 2000) também em campo.

Para a coleta das amostras de água foram utilizados frascos devidamente esterilizados, etiquetados e preparados com reagentes químicos recomendados a cada parâmetro. Depois de coletadas, as amostras foram mantidas sob refrigeração até o início das análises laboratoriais (no máximo 24 e/ou 48 horas após a coleta), conforme o Guia Nacional de Coleta e Preservação de Amostras elaborado pela CETESB (2011).

As variáveis temperatura, turbidez, resíduos totais, $\mathrm{pH}$, nitrogênio total, fósforo total, $\mathrm{DBO}_{5}$, oxigênio dissolvido e Escherichia coli, foram selecionadas, por comporem o quadro de variáveis consideradas para o cálculo do Índice de Qualidade da Água (IQA), conforme CETESB (2014). Para o cálculo do IQA são consideradas nove variáveis limnológicas de acordo com suas curvas de variação e um peso relativo (Tabela 1) calculando o produto ponderado correspondente a cada variável de acordo com a equação 1.

Tabela 1: Variáveis que compõem o IQA e seus respectivos pesos relativos

\begin{tabular}{lll}
\hline Parâmetro & Unidade de Medida & Peso relativo \\
\hline Oxigênio dissolvido & $(\mathrm{mg} / \mathrm{L})$ & 0,17 \\
Escherichia coli & $(\mathrm{NMP} / 100 \mathrm{~mL})$ & 0,15 \\
$\mathrm{pH}$ & - & 0,12 \\
$\mathrm{DBO}$ & $(\mathrm{mg} / \mathrm{L})$ & 0,10 \\
Temperatura & ${ }^{\circ} \mathrm{C}$ & 0,10 \\
Nitrogênio total & $(\mathrm{mg} / \mathrm{L})$ & 0,10 \\
Fósforo total & $(\mathrm{mg} / \mathrm{L})$ & 0,10 \\
Turbidez & $(\mathrm{UNT})$ & 0,08 \\
Resíduos totais & $(\mathrm{mg} / \mathrm{L})$ & 0,08 \\
\hline
\end{tabular}

\footnotetext{
${ }^{1}$ Processo apreciado e aprovado pelo CEP/UNEMAT conforme CAAE: 42350315.6.0000.5166.

2 Laboratório Analítica cadastrado na SEMA-MT ( $\left.{ }^{\circ} 306\right)$, CRQ-MT (N 164) e VISA-CM 95947 (N³51646).
} 


$$
I Q A=\prod_{i=1}^{n} q i^{w i}
$$

Em que:

IQA: Índice de Qualidade das Águas; qi: qualidade do i-ésimo parâmetro, obtido da respectiva curva média de variação de qualidade, em função de sua concentração ou medida e, wi: peso correspondente ao i-ésimo parâmetro, atribuído em função da sua importância para a conformação global de qualidade, sendo que:

$$
\sum_{i=1}^{n} W i=1
$$

Em que:

n: número de variáveis que entram no cálculo do IQA.

O cálculo do IQA determina então a categoria da qualidade da água do recurso hídrico considerando valores entre 0 e 100 conforme Tabela 2. Este método já foi amplamente utilizado por muitos estudos de qualidade da água como, Cornelli et al. (2016), Amorim et al. (2017), Pedroso et al. (2017).

Tabela 2: Categorias do Índice de Qualidade da Água.

\begin{tabular}{ll}
\hline Categoria & Ponderação \\
\hline Ótima & $79<1 \mathrm{IQA} \leq 100$ \\
Boa & $51<1 \mathrm{IQA} \leq 79$ \\
Regular & $36<1 \mathrm{IQA} \leq 51$ \\
Ruim & $19<1 \mathrm{IQA} \leq 36$ \\
Péssima & $\mathrm{IQA} \leq 19$ \\
\hline
\end{tabular}

\section{Análise e interpretação dos dados}

As variáveis foram relacionadas com a litologia e o uso da terra do entorno do córrego e subsidiaram discussões considerando as legislações vigentes do Conselho Nacional do Meio Ambiente - CONAMA 357/05 complementada e alterada pela resolução n 430/11 e Ministério da Saúde - MS 2914/11. Destaca-se ainda que todos os parâmetros limnológicos foram analisados considerando os períodos amostrais (chuvoso/estiagem).

\section{RESULTADOS}

\section{Caracterização ambiental da bacia}

O levantamento das unidades geológicas demostra que aproximadamente $50 \%$ da área total da bacia é ocupada pela Formação Araras que está presente apenas no alto e médio curso (Figura 3) enquanto as outras unidades geológicas estão as formações Raizama (13,16\%), Cobertura Detrítica Laterítica (12,78\%), Moendas (12,07\%), Sepotuba (5,92\%), rochas do Grupo Cuiabá $(4,64 \%)$ e aluviões holocênicos $(0,82 \%)$ conforme Tabela 3.

Tabela 3: Área e percentual de abrangência das unidades geológicas da bacia hidrográfica do córrego Jacobina, município de Cáceres/MT, Brasil.

\begin{tabular}{lll}
\hline Unidade geológica & Área $\left(\mathbf{K m}^{\mathbf{2}}\right)$ & Frequência (\%) \\
\hline Aluviões Holocênicos & 3,68 & 0,82 \\
Cobertura Detrítico-Laterítica & 57,02 & 12,78 \\
Formação Araras & 225,90 & 50,61 \\
\hline
\end{tabular}




\begin{tabular}{lll}
\hline Formação Moendas & 53,89 & 12,07 \\
Formação Raizama & 58,72 & 13,16 \\
Formação Sepotuba & 26,43 & 5,92 \\
Grupo Cuiabá & 20,69 & 4,64 \\
TOTAL & $\mathbf{4 4 6 , 3 4}$ & $\mathbf{1 0 0 , 0 0}$ \\
\hline
\end{tabular}

No alto curso da bacia hidrográfica registram-se a ocorrência das seguintes formações geológica: Raizama, Araras e Moendas e Grupo Cuiabá, com predominância das Formações Moendas e Araras. No médio curso, estão presentes as Formações Araras, Sepotuba, Moendas, Raizama e um pequeno trecho de material pertencente ao Grupo Cuiabá e no baixo curso da bacia são encontradas rochas da Formação Raizama, além de uma faixa predominante de cobertura detrítico-laterítico pleistoscênica e aluviões holocênicos (Figura 2).

A aplicação dos questionários permitiu identificar que, em relação ao tipo de uso e ocupação da terra do entorno, no alto curso da bacia o uso da terra inclui criação de gado bovino e suíno, plantio de soja, milho, milheto e sorgo em alta escala em que a produção é voltada para exportação e produção de ração animal e banana e mandioca em pequena escala para a agricultura de subsistência. No médio curso da bacia o uso da terra é direcionado para a pastagem e o cultivo de teca. No baixo curso a área é destinada a pastagem para criação de gado de forma intensiva e extensiva bem como para o plantio de soja e milho em larga escala. Ademais, no baixo curso estão concentradas algumas pousadas da região tendo em vista a proximidade com o rio e as atividades turísticas e de pesca desenvolvidas no Pantanal.

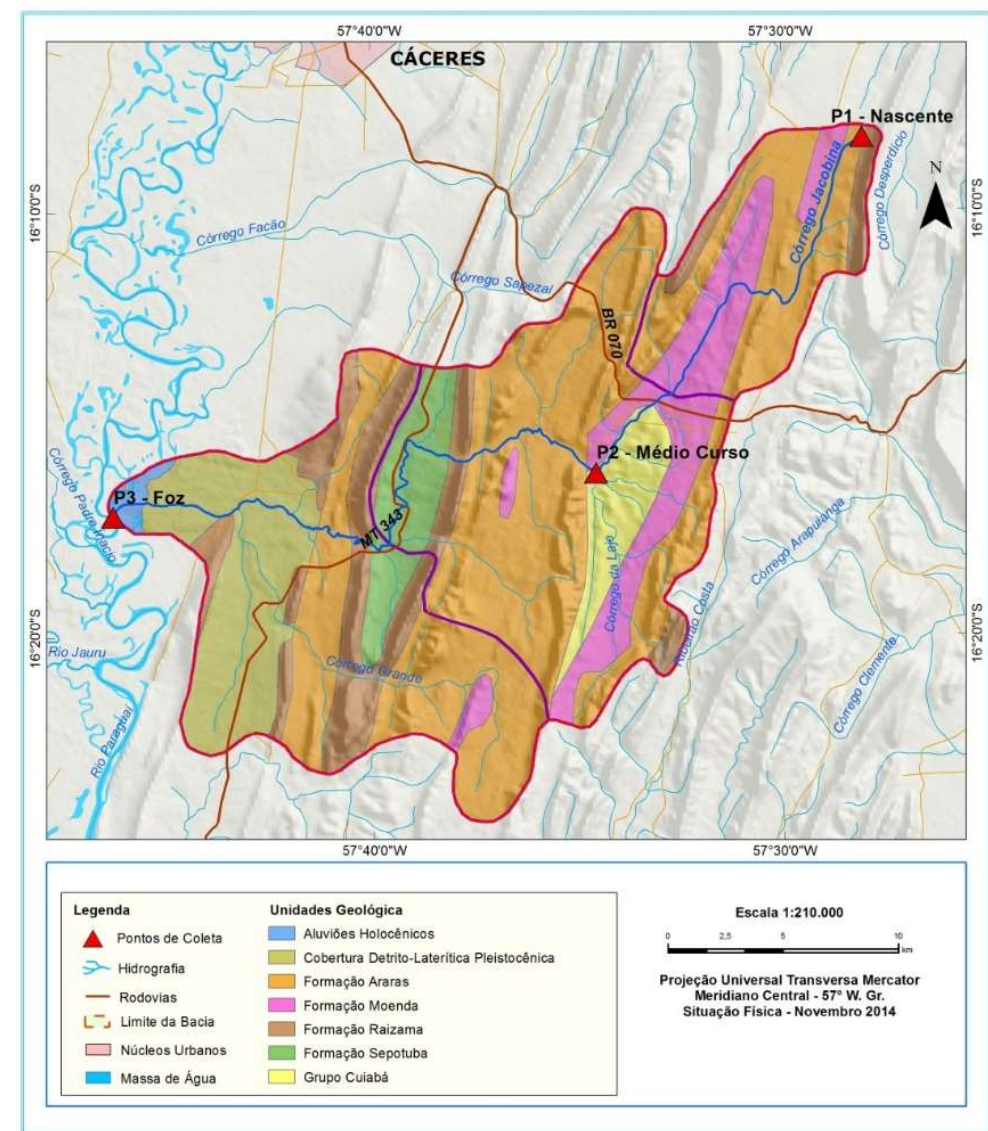

Figura 2: Unidades geológicas da bacia hidrográfica do córrego Jacobina, Cáceres/MT, Pantanal Norte.

\section{Qualidade da água}




\section{Variáveis limnológicas}

Os resultados da análise das variáveis limnológicas estão representados na Tabela 4 e demonstram que apenas as variáveis E. coli, DBO, OD e turbidez para alguns pontos ou períodos amostrais encontram-se em desacordo com a legislação vigente.

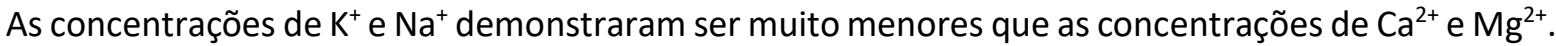
No período de estiagem as concentrações dos cátions monovalentes estiveram abaixo do limite de detecção, enquanto as concentrações dos cátions bivalentes aumentaram consideravelmente confirme Figura 3, especialmente a de $\mathrm{Mg}^{2+}$ que aumentou cerca de 3 vezes mais no ponto 2, embora os limites de nenhum desses íons sejam contemplados nas legislações vigentes (Tabela 4).

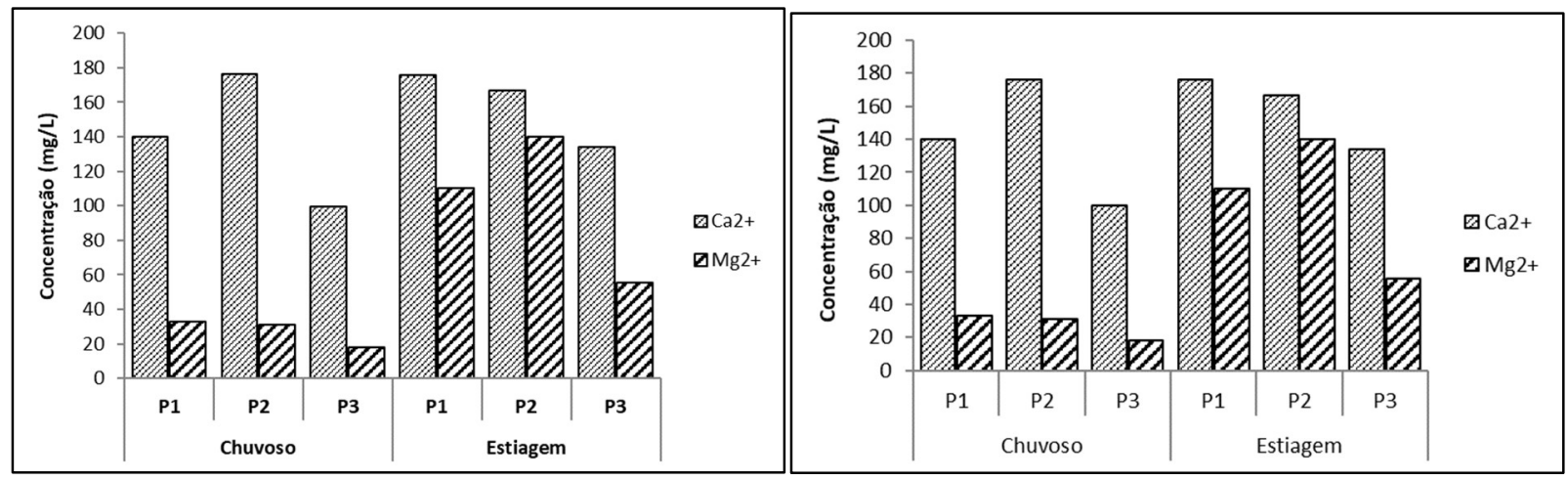

Figura 3: Concentração de cátions bivalentes para os três pontos de coleta nos períodos de cheia e seca do córrego Jacobina, Cáceres/MT.

Apenas o ponto 3 no período chuvoso apresentou concentração de OD abaixo do que determina a Resolução 430/11 do CONAMA, apresentando $0,34 \mathrm{mg} / \mathrm{L}$ quando pela legislação este valor não poderia estar abaixo de $5 \mathrm{mg} / \mathrm{L}$ (Tabela 4; Figura 4).

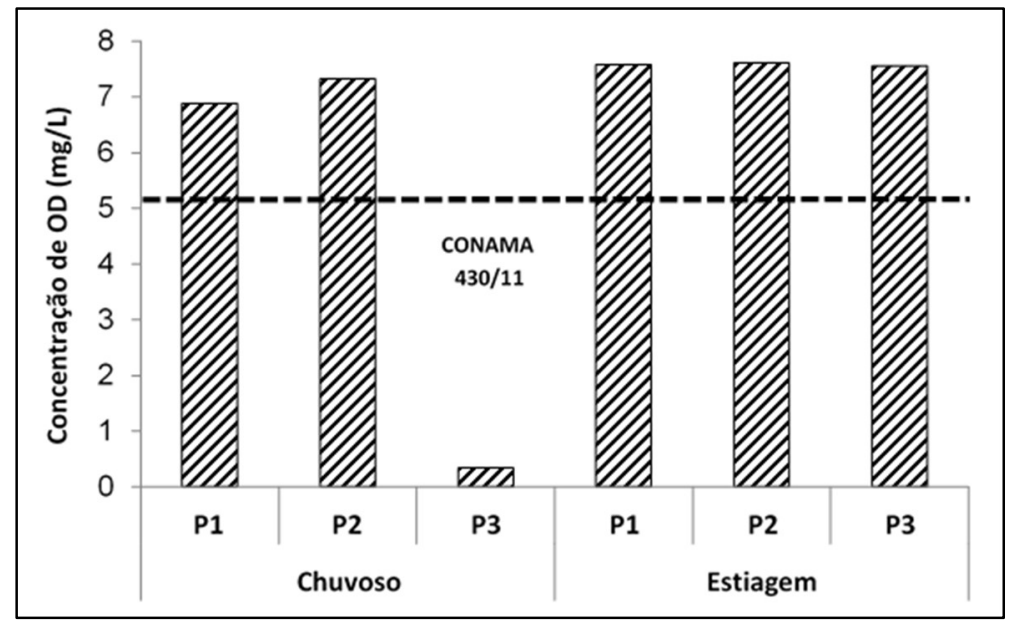

Figura 4: Concentração de oxigênio dissolvido nos pontos de coleta e períodos amostrais para o córrego Jacobina, Cáceres/MT. 
Tabela 4: Variáveis limnológicas das seções de amostragem para os períodos chuvoso e estiagem do córrego Jacobina, Cáceres/MT, Pantanal, 2015.

\begin{tabular}{|c|c|c|c|c|c|c|c|c|}
\hline \multirow[t]{3}{*}{ VARIÁVEL } & \multicolumn{6}{|l|}{ PERÍODO } & \multicolumn{2}{|c|}{ LEGISLAÇÃO } \\
\hline & \multicolumn{3}{|c|}{ CHUVOSO } & \multicolumn{5}{|c|}{ ESTIAGEM } \\
\hline & P1 & $\mathbf{P 2}$ & P3 & P1 & $\mathbf{P 2}$ & P3 & CONAMA & MS \\
\hline & & & & & & & $357 / 05$ & 2914/11 \\
\hline Alcalinidade de bicarbonato (mg/L) & 276,95 & 276,34 & 118,08 & 307,36 & 337,26 & 267,72 & - & \\
\hline Cálcio (mg/L) & 140,08 & 176,33 & 99,49 & 175,76 & 166,76 & 133,95 & - & \\
\hline Cloreto (mg/L) & 3 & 3 & 2 & 1 & 2 & 3 & $\leq 250$ & $\leq 250$ \\
\hline termotolerantes & 30 & 40 & 150 & 44 & 52 & 90 & $\leq 1000$ & - \\
\hline Condutividade elétrica ( $\mu \mathrm{s} / \mathrm{cm}$ ) & 484 & 484 & 101,7 & 581 & 600 & 487 & - & \\
\hline $\mathrm{DBO}_{5}(\mathrm{mg} / \mathrm{L})$ & 0,5 & 0,8 & 8,38 & 0,3 & 0,6 & 1,2 & $\leq 5$ & \\
\hline DQO & 1,2 & 2 & 25,16 & 1 & 1,7 & 4 & - & \\
\hline Dureza total (mg/L de $\left.\mathrm{CaCO}_{3}\right)$ & 277,48 & 305,29 & 175,3 & 299 & 302,3 & 197,1 & - & $\leq 500$ \\
\hline Escherichia coli (NMP/100mL) & Ausente & 10 & 80 & Ausente & 17 & 45 & - & 0 \\
\hline Fósforo total (mg/L) & 0,01 & 0,01 & 0,01 & 0,02 & 0,01 & 0,01 & $\leq 0,03$ & \\
\hline Magnésio (mg/L) & 32,97 & 30,95 & 18,19 & 110,02 & 140,2 & 55,4 & - & \\
\hline Nitrato $(\mathrm{mg} / \mathrm{L})$ & 1,16 & 1,32 & 2,53 & 0,33 & 0,57 & 1,3 & $\leq 10$ & $\leq 10$ \\
\hline Nitrogênio amoniacal (mg/L) & 0,1 & 0,18 & 0,3 & 0,02 & 0,06 & 0,2 & $\leq 3,7$ & \\
\hline Nitrogênio total (mg/L) & 1,28 & 1,54 & 2,89 & 0,4 & 0,7 & 1,59 & - & \\
\hline Oxigênio dissolvido (mg/L) & 6,88 & 7,33 & 0,34 & 7,58 & 7,61 & 7,56 & $\geq 5$ & \\
\hline $\mathrm{pH}$ & 7,88 & 8,16 & 7,02 & 8,68 & 8,44 & 8,35 & 6,0 a 9,0 & 6,0 a 9,5 \\
\hline Potássio (mg/L) & 0,7 & 1 & 0,6 & 0 & 0 & 0 & - & \\
\hline Resíduos totais (mg/L) & 43,67 & 156,66 & 83,33 & 373 & 401 & 330 & - & \\
\hline Sódio (mg/L) & 1,82 & 3,07 & 1,89 & 0 & 0 & 0 & - & $\leq 200$ \\
\hline Sólidos suspensos (mg/L) & 3,6 & 12 & 6,2 & 4,25 & 2 & 14,9 & - & \\
\hline Sólidos dissolvidos (mg/L) & 390 & 364 & 24 & 368,9 & 392,83 & 322 & $\leq 500$ & $\leq 1000$ \\
\hline Sulfato (mg/L) & 2 & 1 & 1 & 2,69 & 2,95 & 5,46 & $\leq 250$ & $\leq 250$ \\
\hline Temperatura $\left({ }^{\circ} \mathrm{C}\right)$ & 28,5 & 27,6 & 28 & 22,8 & 22,3 & 23,3 & - & \\
\hline Turbidez (UNT) & 26,5 & 15,2 & 9,73 & 0,1 & 0,18 & 0,34 & $\leq 100$ & $\leq 5$ \\
\hline
\end{tabular}

\section{Índice de Qualidade da Água (IQA)}

Os dados relativos ao cálculo do Índice de Qualidade da Água dos pontos e períodos amostrais demonstraram que com exceção do P3 no período chuvoso, todos os outros pontos e períodos apresentaram valores de IQA na categoria 'Ótima' (Tabela 5).

Tabela 5: Classificação do IQA nos pontos amostrais de acordo com o período amostrado para o córrego Jacobina, Cáceres/MT.

\begin{tabular}{llll}
\hline Período & Compartimento & IQA & Categoria \\
\hline \multirow{3}{*}{ Chuvoso } & Alto curso & 86 & Ótima \\
& Médio curso & 82 & Ótima \\
& Baixo curso & 47 & Regular \\
\hline \multirow{3}{*}{ Estiagem } & Alto curso & 87 & Ótima \\
& Médio curso & 82 & Ótima \\
& Baixo curso & 80 & Ótima \\
\hline
\end{tabular}

\section{DISCUSSÃO}

As águas dos rios brasileiros são comumente turvas em regiões com solos erodíveis em que as precipitações podem carrear facilmente partículas de argila, silte, areia e fragmentos de rochas em decorrência da geologia da bacia de drenagem (LIBÂNEO, 2010). Desta forma acredita-se que o aumento considerável dos valores de turbidez observados da estação chuvosa (Tabela 4), esteja associado à precipitação que carrega sedimentos para dentro do córrego elevando assim a turbidez das águas.

As condições apresentadas pela turbidez da água podem ter sido influenciadas pelo aspecto hidrológico, uma vez que o intermédio entre cheia-vazante é influenciado pela posição e declividade do 
terreno que dificultam o escoamento das águas (SOUZA et al., 2010). Como consequência disso, ocorrem inundações nas áreas adjacentes que cercam o rio, como nas matas ciliares, fazendas e áreas com grandes quantidades de matéria orgânica disponíveis para serem trazidas para o leito do rio, aumentando assim a turbidez da água nesse período (ARAUJO et al., 2018).

O material concentrado na superfície da água pode consideravelmente influenciar parâmetros como alcalinidade, $\mathrm{CE}$ e $\mathrm{pH}$, por exemplo, que por sua vez podem ser influenciados pelos períodos hidrológicos. $\mathrm{O}$ aumento de $126 \%$ do período de estiagem para chuvoso no P3 nos valores de alcalinidade e de 11 e $22 \%$ em P1 e P2 respectivamente indicam que a água possui boa capacidade de tamponamento. É possível que exista uma estreita relação entre os valores apresentados com a geologia da bacia, pois estudos realizados por Azevedo et al. (2014) e Parron et al. (2009), relacionam as concentrações do ânion bicarbonato $\left(\mathrm{HCO}_{3}{ }^{-}\right)$com os litotipos encontrados em um aquífero e um córrego rural respectivamente. Os primeiros autores, encontraram variações entre $210,9 \mathrm{mg} / \mathrm{L}$ no período chuvoso e $220,9 \mathrm{mg} / \mathrm{L}$ no período seco. Já nos estudos de Parron et al. (2009) os valores variaram de $130 \mathrm{mg} / \mathrm{L}$ a $200 \mathrm{mg} / \mathrm{L}$ considerando os períodos chuvoso, chuvoso-seco, seco e seco-chuvoso, aumentando a concentração de bicarbonato gradativamente.

Assim, não surpreendentemente, a presença do calcário na bacia do córrego Jacobina, pode ter exercido forte influência sobre esta variável, uma vez que, geologicamente a bacia está inserida principalmente na Formação Araras que é constituída de rochas carbonáticas de calcários dolomíticos em maior abundância.

Embora não tenha significado sanitário, a CE pode indicar a presença de sais dissolvidos na água que podem ter origem tanto de ordem natural quanto antrópica. Nascimento et al. (2014) demonstraram que existe uma estreita relação entre a $\mathrm{CE}$ das águas com a dissolução dos íons de $\mathrm{Na}^{+}, \mathrm{Mg}^{2+}$ e $\mathrm{Cl}^{-}$. Seus estudos apresentaram valores de condutividade semelhantes aos encontrados nesta pesquisa com $384 \mu \mathrm{s} / \mathrm{cm}$ em águas subterrâneas de formação geológica arenítica e calcária, similares às condições geológicas da bacia do córrego Jacobina. Elevados valores CE também foram observados por Oliveira et al. (2017) nas condições de

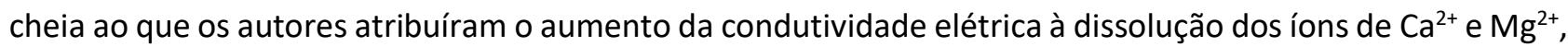
o que demonstra condições opostas ao nosso estudo, uma vez que a CE esteve consideravelmente maior na estiagem do que no período de águas altas.

Este fato também pode estar correlacionado ao fator de diluição que o período de águas altas provoca no Pantanal, distribuindo seus íons, portanto diminuindo a concentração destes, o contrário ocorrendo no período de estiagem, onde os íons estão mais concentrados e com menor vazão hídrica. Ainda, mesmo que as legislações não abranjam este tipo de parâmetro, ressalta-se que esta variável pode conduzir a interpretações importantes na análise da qualidade do recurso hídrico no Pantanal.

A condutividade e a alcalinidade estão intimamente ligadas aos resultados de $\mathrm{pH}, \mathrm{o}$ qual representa a concentração de íons $\mathrm{H}^{+}$presentes no sistema e expressa as características ácidas ou alcalinas (básicas) da água. As águas naturais de superfície, apresentam pH entre 6,0 e 8,5, ideal para a manutenção da vida aquática (LIBÂNEO, 2010), reforçada pela resolução 357/05 do CONAMA que preconiza que águas doces de classe II devem manter o pH na faixa entre 6,0 e 9,0. 
O aumento do valor do $\mathrm{pH}$ observado em todas as seções quando comparados os períodos chuvoso e de estiagem, explica-se pelo fato de que as águas da chuva impedem o carbonato de se precipitar e solubiliza-se, assim, no período de estiagem, o carbonato volta a forma precipitada (AZEVEDO et al., 2014). Desta forma, maiores valores de $\mathrm{pH}$ estiveram relacionados com o substrato rochoso de calcário observado por Parron et al. (2009) em córregos da bacia hidrográfica do Rio Preto e Barros et al. (2012) no córrego André em Mirassol D'Oeste/MT.

Destaca-se ainda que a estruturação da Formação Araras é constituída por rochas carbonáticas, caracterizadas pela presença de calcário que por sua vez apresenta abundância da mineral calcita (KOHLER, 2008). A dissolução da calcita na água, libera cálcio e carbonatos (ALBERÈDE, 2011), substâncias que podem influenciar a qualidade da água pela influência que exercem no pH, dureza, condutividade elétrica (LIBÂNEO, 2010).

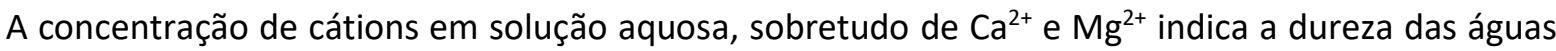
que se manifesta pela resistência à reação de saponificação. Esta característica reflete a natureza geológica da bacia, sendo mais evidente nas regiões de formação calcária (LIBÂNEO, 2010) como é o caso da bacia

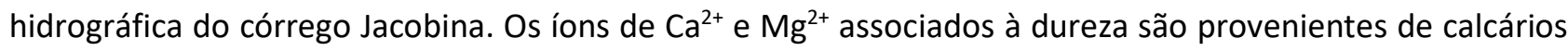
dolomíticos e calcíticos (ALBERÈDE, 2011) frequentemente observados na área de estudo através de afloramentos rochosos no solo no alto e médio curso da bacia (Figura 2).

Estudos realizados por Oliveira et al. (2017) indicaram que, embora com concentrações menores de carbonato de cálcio, a dureza das águas do riacho São Caetano (MA) esteve relacionada à presença de material calcário oriundo do entorno da bacia, condições similares à bacia do córrego Jacobina, o que classifica, portanto, a água do córrego como dura. As águas duras são comumente conhecidas como águas "salobras" pela população, atribuindo uma característica organoléptica de água salgada.

Sabe-se que a água dura impede a formação de espumas usualmente causadas pelos sabões, dificultando alguns processos caseiros, além de agregar os íons de cálcio de magnésio, causando incrustações nas tubulações e embora o CONAMA não tenha estabelecido limites para a concentração, pois não há valor sanitário agregado a elas, a Portaria 2914/11 estabelece um limite de 500 mg/L para atender aos padrões de organolépticos de potabilidade da água. Assim, neste estudo, todos os pontos amostrais encontram-se dentro dos padrões.

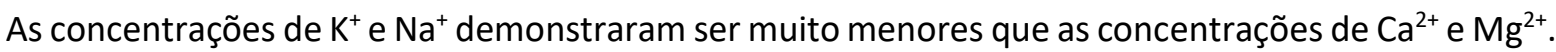
De acordo com Alberède (2011) o potássio e o sódio não formam complexos significativos na água, já o cálcio e o magnésio formam complexos do tipo hidróxidos, carbonatos e sulfatos com a água e ambos são

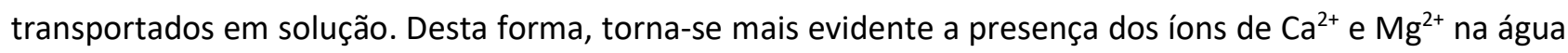
do que dos íons de $\mathrm{K}^{+}$e $\mathrm{Na}^{+}$. Entretanto, o aumento das concentrações de cálcio e magnésio do período chuvoso para o período de estiagem observada em todos os pontos amostrados, também foi evidenciado por Parron et al. (2009) em estudo nos córregos Caxingó e Areia em Minas Gerais que se localizava em terrenos de origem calcária e por Azevedo et al. (2014) em estudo em águas freáticas no estado do Tocantins. Essa variação pode estar associada à diminuição do volume das águas que permite maior concentração 
desses íons.

As concentrações de íons $\mathrm{Cl}^{-}$estão dentro dos limites do que preconiza a legislação (Tabela 4), entretanto, a Portaria 2914/11 do MS relaciona as concentrações de cloretos com os padrões organolépticos da água, que são aqueles que podem alterar as características relacionadas aos sentidos, como o gosto, o cheiro e a cor. $O$ aumento de concentração de cloretos na água é um indicador de possível contaminação de esgotos pela sua presença na urina que tem como consequência a alteração do sabor da água (FERNANDES et al., 2011). O aumento dos níveis de cloreto pode também ter relação com o período hidrológico, aumentando consideravelmente no período chuvoso principalmente devido a constituição rochosa local (PARRON et al., 2009) conforme observado neste estudo.

O mesmo comportamento foi observado para a variação da concentração de sulfatos. Ressalta-se que em águas naturais, a maior fonte do sulfato ocorre através da dissolução de solos e rochas e em menor escala as atividades antrópicas como descargas de esgotos domésticos e efluentes industriais também podem proporcionar a entrada deste íon nas águas superficiais (FERNANDES et al., 2011). Desta forma, as concentrações de sulfatos encontradas na bacia do córrego Jacobina, estariam mais associadas à dissolução dos componentes químicos das rochas do que com o uso da terra no entorno do córrego.

Os resultados demonstraram que tanto as propriedades rurais, quanto as criações de animais observadas nos três pontos amostrais permitem a entrada de coliformes na água, no entanto, não o suficiente para deixar a água inadequada para o consumo, conforme Tabela 4. Coliformes e a bactéria Escherichia coli são variáveis importantes na determinação da qualidade ambiental em vários estudos e dependem principalmente de ações antrópicas como o uso de fossas rudimentares e criação de animais em ambientes rurais (COSTA et al., 2014; SILVA et al., 2016; FERREIRA et al., 2017).

Quando comparados a outros estudos, os valores de bactérias encontrado nos P2 e P3 são relativamente baixos ao analisaram esta mesma variável $\left(4,4 \times 10^{2} \mathrm{UFC} / 100 \mathrm{~mL}\right.$ na estação seca a $8,7 \times 10^{3}$ UFC/100 mL na estação chuvosa em estudo realizado no córrego Rico em Jaboticabal SP por Silva et al. (2016)); ou ainda que mais baixos como em levantamento realizado por um autor em 2019 que registraram de 140 a 170 NMP/100 mL em água do córrego Paraíso, no Espírito Santo ao que os autores atribuíram ao lançamento de esgotos domésticos no curso d'água sem o devido tratamento prévio.

Estudos realizados na bacia do córrego Sujo em Teresópolis/RJ registraram valores para esta variável entre $2,0 \times 10^{2}$ UFC a $8,9 \times 10^{2}$ UFC ao que os autores destacam a relevância para áreas de culturas irrigadas (ARAUJO et al., 2015) que constitui um dos tipos de uso do entorno do córrego Jacobina. Para Vanzela et al. (2010) a concentração de coliformes no córrego Três Barras em Marinópolis, é oriunda principalmente das moradias rurais que agregam lixos e esgotos domésticos além da criação de animais tais como suínos, aves e bovinos, da mesma forma que ocorre no entorno do córrego Jacobina. Outro fator que pode ser associado à presença desses organismos na água é a utilização de adubos com esterco nas culturas praticadas na bacia, principalmente, as culturas irrigadas, pois este material seria mais facilmente escoado para o curso d'água.

A diminuição da concentração de $E$. coli observada no P3 pode ser explicada pelo fato deste ponto estar localizado à jusante de duas pousadas localizadas na margem do rio Paraguai, assim, na estação chuvosa 
esta seção pode sofrer influência das águas do rio e o esgoto dessas pousadas pode estar sendo diluído pelas águas. O pequeno aumento observado no P2 pode estar relacionado com o acúmulo de dejetos no canal fluvial, oriundos da criação de animais, pois esse material é carreado de montante para jusante e se dispersa nas águas, no entanto, no período chuvoso as águas tendem a ter maior turbulência, enquanto que com menor volume de água no período de estiagem, o carreamento do material é mais lento, já que, altos valores de coliformes termotolerantes estão relacionados com os níveis de precipitação que ocasionam escoamento dos dejetos e resíduos da superfície para o leito dos mananciais (KUHLMANN et al., 2014).

Embora o P3 tenha apresentado valor superior ao que estabelece a resolução 357/05 do CONAMA para a DBO (Tabela 4), a maioria dos pontos esteve bem abaixo do permitido apresentando diminuição de consumo de oxigênio, quando comparado os períodos chuvoso e estiagem o que sugere um ambiente aquático em boas condições. A mesma tendência pode ser observada para a DQO, que apresentou valores pouco representativos, com exceção do P3 e diminuição do consumo de oxigênio.

$\mathrm{O}$ aumento considerável de consumo de oxigênio no $\mathrm{P} 3$, no período chuvoso pode ser explicado por alguns motivos: este ponto é a foz do córrego Jacobina que quando deságua no rio Paraguai forma uma espécie de baía de águas muito lentas, o que permite a maior concentração de matéria orgânica; à montante estão localizadas duas pousadas que podem eventualmente realizar o descarte de esgoto no rio; a Fazenda Ressaca que está nos limites do ponto de coleta pratica pecuária de corte intensiva e extensiva, que produz dejetos animais e culturas de soja e milho que utiliza adubos e outros materiais orgânicos. Todo esse material escoa mais facilmente através das águas das chuvas e pode alcançar a foz do córrego e se concentrar, desta forma, os organismos biodegradadores precisam consumir mais oxigênio para conseguir decompor a matéria orgânica.

O consumo de oxigênio para decomposição da matéria orgânica pode ter influenciado as pequenas concentrações de $\mathrm{OD}$ no $\mathrm{P} 3$, as atividades antrópicas associadas ao alto valor encontrado de $\mathrm{DBO}_{5}$, pois quanto maior a demanda bioquímica de oxigênio, menor será a concentração de $O D$, uma vez que as bactérias utilizam esse gás para degradar a matéria orgânica presente no ecossistema. Ademais, o P 3 é o destino final das águas do córrego Jacobina, assim, recebe todo o material dissolvido e em suspensão das águas que terminam por acumular-se nesta baía e desta forma aumentar a quantidade de matéria orgânica ali presente.

Valores semelhantes e também abaixo do que preconiza a legislação ao da maioria dos pontos deste estudo foram encontrados por Sampaio et al. (2018) em que os autores relacionaram as médias de valores de oxigênio dissolvido com o lançamento de efluentes residenciais no rio dos Bugres em São Paulo que lixiviam nutrientes para os corpos d'água e terminam por contribuir com o crescimento de macrófitas aquáticas, efeito também observado na foz do córrego Jacobina. Marçal et al. (2017) associaram as médias de OD (6 mg/L) obtidas em estudo no rio Parnaíba como impacto da estação de tratamento de efluentes e atribuíram as oscilações das concentrações de oxigênio na água ao material lançado nos corpos d'água, ratificando a ideia de que a entrada de material orgânico no ponto 3 do córrego Jacobina promove a queda de OD na água. 
Com relação à concentração de nutrientes na água, destaca-se que o controle do PT nos ambientes aquáticos está relacionado ao seu ciclo natural que tem sua entrada no ecossistema através da decomposição de plantas e animais e que quando atinge a coluna d'água pode provocar, dependendo de alguns fatores, processos como a eutrofização, alterando a qualidade hídrica (PANTANO et al., 2016).

A entrada deste elemento na água pode ser favorecida por diferentes maneiras tais como atividades pesqueiras relatadas por Piasentin et al. (2009); lançamentos de esgotos domésticos identificado por Barros et al. (2012) e práticas agrícolas relatadas por Amorim et al. (2017), de maneira que neste estudo podem estar associadas ao uso de agrotóxicos/fertilizantes e produtos afins utilizados nas culturas que se processam no entorno do córrego Jacobina nas três seções amostrais.

As fontes de nitrogênio para o ambiente aquático podem ocorrer através do carreamento de material orgânico alóctone tais como lançamento de efluentes e de fertilizantes utilizados na agricultura e em menor escala, a criação de animais. A resolução 357/05 do CONAMA estabelece o limite de $10 \mathrm{mg} / \mathrm{L}$ de nitrato, 1,0 $\mathrm{mg} / \mathrm{L}$ de nitrito e o nitrogênio amoniacal tem seus limites definidos a partir do $\mathrm{pH}$ apresentado pelas águas. Assim, para cada ponto amostral, ao comparar a concentração de nitrogênio amoniacal com a resolução, foi necessário relacionar com os valores de $\mathrm{pH}$ apresentados.

Comparadas a outros estudos realizados, as concentrações de nitrogênio são muito baixas. Bühler et al. (2013) encontraram concentrações de nitrato de 0,10 a 3,7 mg/L em trecho urbano do rio Paraguai em Cáceres/MT; Almeida et al. (2012) encontrou concentrações de nitrato entre 0,1 e 1,4 mg/L em águas destinadas à recreação no rio Protero de Los Funes na Argentina.

Considera-se que nesta bacia, a concentração de NT na água esteja associada às atividades de criação de animais que produzem excrementos ricos em nutrientes como o nitrogênio, aos adubos naturais utilizados na agricultura de pequena escala como banana e mandioca e aos fertilizantes utilizados nas culturas em grande escala como milho e soja, especialmente no ponto 3 que teve as maiores concentrações tanto no período chuvoso quanto no período de estiagem.

Considerando os pesos relativos de cada uma das variáveis, acredita-se que a saturação do oxigênio dissolvido e a variável $E$. coli tenham sido as duas variáveis de maior impacto sobre o valor de IQA apresentado para o ponto três, pois são essas, as variáveis de maiores pesos com 0,17 e 0,15 respectivamente.

Alguns estudos que utilizaram IQA como instrumento de avaliação da qualidade da água nos estados de Mato Grosso e Mato Grosso do Sul. Ao estudar sobre a qualidade da água superficial do rio Caiabi, ao norte do estado, em que todos os pontos amostrados receberam a ponderação 'Boa', ao que os autores atribuíram a presença da mata ciliar e a cobertura vegetal do entorno do curso d'água. Por outro lado, Barros et al. (2012) identificaram que as águas do córrego Guanandy, em Aquidauana/MS, oscilaram entre as categorias "Ruim" e "Muito Ruim" em trechos urbanos e rurais em diferentes períodos do ano, variável que os autores utilizam para explicar a relativa melhora na qualidade da água.

Estudos realizados nesta perspectiva demonstraram que o IQA funciona como uma ferramenta não somente para a determinação da qualidade de um recurso hídrico, mas também para a gestão do mesmo. 
Pedroso et al. (2017) demonstraram valores de IQA ( \pm 83) bastante semelhantes ao deste estudo para diferentes pontos da bacia hidrográfica do Ribeirão da Areia/GO e assim como na bacia do córrego Jacobina, a variação esteve relacionada à produção agropecuária e ao abastecimento das propriedades rurais. Piratoba et al. (2017) aplicaram o Índice de Qualidade da Água para determinar a influência do lançamento de resíduos industriais em corpos d'água da zona portuária de Bacarena (PA) demonstrando que embora as atividades do entorno exerçam influência na qualidade da água, a sazonalidade foi mais determinante, o que se contrapõe aos dados deste estudo, em que a maioria dos pontos amostrais não apresenta diferença no IQA para os diferentes períodos sazonais.

\section{CONCLUSÕES}

O cálculo do IQA demonstrou ser uma importante ferramenta de análise da qualidade da água, no entanto, estudos com esta perspectiva não devem se restringir apenas a este método, pois este índice considera apenas algumas variáveis que possuem valor sanitário mais imediato, sendo que outras variáveis assumem importância nos padrões de potabilidade da água.

Entre as variáveis limnológicas analisadas, algumas estão possivelmente relacionadas com o material litológico da bacia, especialmente o calcário, como alcalinidade, condutividade elétrica, cálcio, magnésio, potássio, sódio, cloreto, sulfato, dureza e pH, indicando que a qualidade da água do córrego Jacobina pode ser influenciada pela geologia. Outras variáveis podem ser explicadas pelo tipo de uso da terra, especialmente $E$. coli proveniente da criação de animais e nutrientes como nitrogênio e fósforo provenientes das áreas reservadas para as culturas irrigadas.

Portanto, considera-se que os pontos estudados sofrem com a presença de $E$. coli córrego abaixo, e variam de acordo com as estações hidrológicas. Assim, entende-se que, sendo esta bactéria bastante preocupante para a qualidade hídrica e, sobretudo para a saúde humana, o córrego pantaneiro apresenta potencial de contaminação devido provavelmente a criação de gado e ao despejo de esgoto de pousadas circunvizinhas.

A partir deste estudo foi possível relacionar as atividades desenvolvidas no entorno do córrego Jacobina, bem como as características naturais do ambiente como a geologia, com a qualidade da água. No entanto, estudos estatísticos são necessários a fim de se obter um diagnóstico completo que correlacione os elementos ambientais.

\section{REFERÊNCIAS}

ALBERÈDE, F.. Geoquímica: uma introdução. São Paulo: Oficina de Textos, 2011.

ALMEIDA, C.; GONZÁLEZ, S. O.; MALLEA, M.; GONZÁLEZ, P. $A$ recreational water quality index using chemical, physical and microbiological parameters. Environmental Science and Pollution Research International, v.19, n.8, p.3400-3411, 2012. DOI: http://doi.org/10.1007/s11356-012-0865-5

AMORIM, D. G.; CAVALCANTE, P. R. S.; SOARES, L. S.; AMORIM, P. E. C.. Enquadramento e avaliação do índice de qualidade da água dos igarapés Rabo de Porco e Precuá, localizados na área da Refinaria Premium I, município de Bacabeira (MA). Engenharia Sanitária e Ambiental, v.22, n.2, p.251-259, 2017. DOI: http://doi.org/10.1590/S1413 • 41522016131212

ANA. Agência Nacional das Águas. Portal da Qualidade das Águas. Brasília: ANA, 2015.

APHA; AWWA; WEF. American Public Health Association. American Water Works Association; Water Pollution Control 
Federation. Standard methods for the examination of water and wastewater. 22 ed. Washington: APHA, 2012.

ARAUJO, F. V.; VIEIRA, L.; JAYME, M. M. A.; NUNES, M. C.; CORTÊS, M.. Avaliação da qualidade da água utilizada para irrigação na bacia do Córrego Sujo, Teresópolis, RJ. Cadernos de Saúde Coletiva, Rio de Janeiro, v.23, n.4, p.380-385, 2015. DOI: http://dx.doi.org/10.1590/1414462X201500040083

AZEVEDO, J. H.; CAMPOS, J. E. G.; BOAVENTURA, G. R.. Influência dos fatores geológicos e hidrogeológicos na estabilidade química das águas freáticas no sul do estado do Tocantins. Revista Geociências, v.33, n.1, p.73-88, 2014.

BARROS, R. V. G.; SOUZA, C. A.. Qualidade do recurso hídrico do Córrego André, Mirassol D’Oeste, MT. Revista Brasileira de Ciências Ambientais, n.24, p.01-16, 2012.

BRASIL. Portaria n. 2914. Dispõe sobre os procedimentos de controle e de vigilância da qualidade da água para consumo humano e seu padrão de potabilidade. Brasília: DOU, 2011.

BRASIL. Resolução n. 357. Dispõe sobre a classificação dos corpos de água e diretrizes ambientais para o seu enquadramento, bem como estabelece as condições e padrões de lançamento de efluentes, e dá outras providências. Brasília: DOU, 2005.

BRASIL. Resolução n. 430. Dispõe sobre as condições e padrões de lançamento de efluentes, complementa e altera a Resolução n. 357, de 17 de março de 2005, do Conselho Nacional do Meio Ambiente. Brasília: CONAMA, 2011.

BRASIL. Ministério das Minas e Energia. Projeto RADAMBRASIL. Folha SD. 21 - Cuiabá: Geologia, Geomorfologia, Pedologia, Vegetação e Uso potencial da terra. Secretaria Geral. Rio de Janeiro: MME, 1982.

BONI, V.; QUARESMA, S. J.. Aprendendo a entrevistar: como fazer entrevistas em Ciências Sociais. Revista Eletrônica dos Pós-Graduandos em Sociologia Política da UFSC, v.2, n.1-3, p.68-80, 2005.

BÜHLER, B. F.; SOUZA, C. A.; OLIVEIRA JUNIOR, E. S.. Qualidade da água do rio Paraguai no perímetro urbano em Cáceres/MT, Brasil. Revista GeoPantanal, v.8, n.14, p.67-89, 2013.

CETESB. Companhia Ambiental do Estado de São Paulo. Qualidade das águas superficiais no estado de São Paulo 2014. São Paulo: CETESB, 2014.

CETESB. Companhia Ambiental do Estado de São Paulo. Guia nacional de coleta e preservação de amostras: água, sedimento, comunidades aquáticas e efluentes líquidas. São Paulo: CETESB; Brasília: ANA, 2011.

CORNELLI, R.; SCHENEIDER, V. E.; BORTOLIN, T. A.; CEMIN, G.; SANTOS, G. M.. Análise da influência do uso e ocupação do solo na qualidade da água de duas sub-bacias hidrográficas do município de Caxias do Sul. Scientia cum Industria (sci. Cum ind.), v.4, n.1, p.1-14, 2016. DOI: http://dx.doi.org/10.18226/23185279.v4iss1p1

COSTA, C. C.; GUILHOTO, J. J. M.. Saneamento rural no Brasil: impacto da fossa séptica biodigestora. Revista Engenharia
Sanitária e Ambiental, n.19, p.51-60, 2014. DOI: http://dx.doi.org/10.1590/S1413-41522014019010000171

FERREIRA, F. S.; QUEIROZ, T. M.; SILVA, T. V.; ANDRADE, A. C. O.. À margem do rio e da sociedade: a qualidade da água em uma comunidade quilombola no estado de Mato Grosso. Saúde e Sociedade, São Paulo, v.26, n.3, p.822-828, 2017. DOI: http://dx.doi.org/10.1590/s0104-12902017166542

FERNANDES, M. M.; CEDDIA, M. B.; RAMOS, G. M.; GASPAR, A.; MOURA, M. R.. Influência do uso do solo na qualidade de água da microbacia Glória, Macaé/RJ. Revista de Engenharia Ambiental, v.8, n.2, p.115-116, 2011.

FOK, L.; PEART, M. R.; CHEN, J.. The influence of geology and land use on the geochemical baselines of the East River basin, China. Revista Catena, v.101, p.212-225, 2013. DOI: https://doi.org/10.1016/i.catena.2012.09.008

JUNK, W. J.; CUNHA, C. N.; WANTZEN, K. M.; PETERMANN, P.; STRÜSSMANN, C.; MARQUES, M. I.; ADIS, J.. Biodiversity and its conservation in the Pantanal of Mato Grosso, Brazil. Revista Aquatic Sciences, v.68, p.278-309, 2006. DOI: http://doi.org/10.1007/s00027-006-0851-4

KUHLMANN, M. L.; IMBIMBO, H. R. V.; OGURA, L. L.; VILLANI, J. P.; STARZYNSKI, R.; ROBIM, M. J.. Effects of human activities on rivers located in protected areas of the Atlantic Forest. Acta Limnologica Brasiliensia, v.26, n.1, p.60-72, 2014. DOI: http://dx.doi.org/10.1590/S2179975X2014000100008

LAMPTEY, A. M.; OFORI-DANSON, P. K.; ABBENNEYMICKSON, S.; BREUNING-MADSEN, H.; ABEKOE, M. K.. The Influence of Land-Use on Water Quality in a Tropical Coastal Area: Case Study of the Keta Lagoon Complex, Ghana, West Africa. Open Journal of Modern Hydrology, v.3, n.4, p.188195, 2013. DOI: http://doi.org/10.4236/ojmh.2013.34023

LIBÂNEO, M.. Fundamentos de qualidade e tratamento de água. 3 ed. Campinas: Átomo, 2010.

MARÇAL, D. A.; SILVA, C. E.. Avaliação do impacto do efluente da estação de tratamento de esgoto ETE-Pirajá sobre o Rio Parnaíba, Teresina (PI). Revista Engenharia Sanitária e Ambiental, Rio de Janeiro, v.22, n.4, 2017. DOU: http://dx.doi.org/10.1590/s1413-41522017148242

MONTEIRO, J. C.; BACELLAR, L. A. P.. Influência dos fatores geológicos, geomorfológicos e antrópicos da produção de fluxo de base em pequenas bacias hidrográficas na APA Cachoeira das Andorinhas, Ouro preto (MG). Revista Brasileira de Geomorfologia, São Paulo, v.15, n.2, p.173189, 2014. DOI: http://dx.doi.org/10.20502/rbg.v15i2.398

MOSAAD, S.. Geomorphologic and geologic overview for water resources development: Kharit basin, Eastern Desert, Egypt. Journal of African Earth Sciences, v.134, p.56-72, 2017. DOI: http://doi.org/10.1016/j.jafrearsci.2017.06.008

NASCIMENTO, S. A. M.; ALVES, J. E.. Estudo hidrogeoquímico comparativo entre os aquíferos Barreiras, Marizal e São Sebastião na região do Recôncavo Norte, estado da Bahia. Cadernos de Geociências, v.11, n.1-2, p.72-82, 2014.

OLIVEIRA, R. M. M.; SANTOS, E. V.; LIMA, K. C.. Avaliação da qualidade da água do riacho São Caetano, de Balsas (MA), 
com base em parâmetros físicos, químicos e microbiológicos. Revista Engenharia Sanitária e Ambiental, v.22, n.3, p.523-530, 2017. DOI:

https://doi.org/10.1590/s1413-41522017154657.

OLIVEIRA FILHO, A. A.; LIMA NETO, I. E.. Modelagem da qualidade da água do rio Poti em Teresina (PI). Revista Engenharia Sanitária e Ambiental, v.23, n.1, 2017. DOI: http://dx.doi.org/10.1590/s1413-41522017142354

PANTANO, G.; GROSSELI, G. M.; MOZETO, A. A.; FADINI, P. S.. Sustentabilidade no uso do fósforo: uma questão de segurança hídrica e alimentar. Revista Química Nova, v.39, n.6, p.732-740, 2016. DOI: http://dx.doi.org/10.5935/0100$\underline{4042.20160086}$

PARRON, L. M.; LIMA, J. E. F. W.; CRUZ, C. J. D.; FRANCISCON, L.. Geologia, uso da terra e qualidade dos recursos hídricos superficiais na bacia hidrográfica do rio Preto, MG. Revista de Estudos Ambientais, v.11, n.2, p.59-70, 2009.

PEDROSO, L. B.; COLESANTI, M. T. M.. Determinação do índice de qualidade de água da bacia hidrográfica do Ribeirão da Areia - Goiás, em período de estiagem. Revista Caminhos de Geografia, v.18, n.61, p.219-230, 2017.

PIASENTIN, A. M.; SEMENSATTO JUNIOR, D. L.; SAAD, A. R.; MONTEIRO JUNIOR, A. J.; RACZKA, M. F.. Índice de qualidade da água (IQA) do reservatório Tanque Grande, Guarulhos (SP): análise sazonal e efeitos do uso e ocupação do solo. Revista Geociências, v.28, n.3, p.305-317, 2009. DOI: http://hdl.handle.net/11449/71381

REIS, D. A.; SANTIAGO, A. F.; NASCIMENTO, L. P.; OILVEIRA, E. G.; MARQUES, L. S.; ROESER, H. M. P.. Influência dos fatores ambientais e antrópicos nas águas superficiais no rio Matipó, afluente do rio Doce. Revista de Gestão de Água da América Latina, v.14, p.1-15, 2017. DOI: http://doi.org/10.21168/rega.v14e2
SILVA, C. J.; WANTZEN, M.; CUNHA, C. N.; MACHADO, F. A.. Biodiversity in the Pantanal Wetland, Brazil. In: WOLFGANG, J. J.; GOPAL, B.; DAVIS, J. A.. Biodiversity in wetlands: assessment, function and conservation. Leiden: Backhuys, 2001. p.187-215.

SILVA, L. G.; LOPES, L. G.; AMARAL, L. A.. Qualidade da água de abastecimento público do município de Jaboticabal, SP. Revista Engenharia Sanitária e Ambiental, v.21, n.3, 2016. DOI: http://dx.doi.org/10.1590/S1413-41522016121151

SOUZA, A. V. V.; OLIVEIRA, S. M. L.. Análise da qualidade da água do rio Vermelho em Mato Grosso no período de cheia no ano de 2014. Revista Biodiversidade, v.13, n.2, p.115126, 2014.

SOUZA, M. M.; GASTALDINI, M. C. C.. Avaliação da qualidade da água em bacias hidrográficas com diferentes impactos antrópicos. Revista Engenharia Sanitária e Ambiental, Rio de Janeiro, v.19, n.3, 2014. DOI:

http://dx.doi.org/10.1590/S1413-41522014019000001097

SOUZA, C. A.; SOUSA, J. B.. Pantanal mato-grossense: origem, evolução e as características atuais. Revista Eletrônica da Associação dos Geógrafos Brasileiros, v.1, n.11, p.34-54, 2010.

VALDÉS-PINEDA, R.; PIZARRO, R.; GARCIA-CHEVESICH, P.; VALDES, J. B.; OLIVARES, C.; VERA, M.; BALOCCHI, F.; PEREZ, F.; VALLEJOS, C.; FUENTES, R.; ABARZA, A.; HELWIG, B. Water governance in Chile: Availability, management and climate Change. Journal of Hydrology, v.519, 2014.

VANZELA, L. S.; HERNANDEZ, F. B. T.; FRANCO, R. A. M.. Influência do uso e ocupação do solo nos recursos hídricos do Córrego Três Barras, Marinópolis. Revista Brasileira de Engenharia Agrícola e Ambiental, v.14, n.1, p.55-64, 2010.

A CBPC - Companhia Brasileira de Produção Científica (CNPJ: 11.221.422/0001-03) detém os direitos materiais desta publicação. Os direitos referem-se à publicação do trabalho em qualquer parte do mundo, incluindo os direitos às renovações, expansões e disseminações da contribuição, bem como outros direitos subsidiários. Todos os trabalhos publicados eletronicamente poderão posteriormente ser publicados em coletâneas impressas sob coordenação da Sustenere Publishing, da Companhia Brasileira de Produção Científica e seus parceiros autorizados. Os (as) autores (as) preservam os direitos autorais, mas não têm permissão para a publicação da contribuição em outro meio, impresso ou digital, em português ou em tradução. 